\title{
Effects of the Cone and Edge on the Acoustic Characteristics of a Cone Loudspeaker
}

\author{
Yue Hu, ${ }^{1,2}$ Xilu Zhao, ${ }^{2}$ Takao Yamaguchi, ${ }^{3}$ Manabu Sasajima, ${ }^{1}$ \\ Tatsushi Sasanuma, ${ }^{1}$ and Akira Hara ${ }^{1}$ \\ ${ }^{1}$ Foster Electric Company, Limited, 1-1-109 Tsutsujigaoka, Akishima, Tokyo 196-8550, Japan \\ ${ }^{2}$ College of Mechanical Engineering, Saitama Institute of Technology, 1690 Fusaiji, Fukaya, Saitama 369-0293, Japan \\ ${ }^{3}$ Department of Mechanical Science and Technology, Faculty of Science and Technology, Gunma University, \\ 1-5-1 Tenjin-cho, Kiryu, Gunma 376-8515, Japan
}

Correspondence should be addressed to Xilu Zhao; zhaoxilu@sit.ac.jp

Received 8 February 2017; Accepted 15 March 2017; Published 21 May 2017

Academic Editor: Kim M. Liew

Copyright (C) 2017 Yue Hu et al. This is an open access article distributed under the Creative Commons Attribution License, which permits unrestricted use, distribution, and reproduction in any medium, provided the original work is properly cited.

Loudspeakers are designed for reproducing the original sound field as faithfully as possible. In order to faithfully reproduce sound, it is important to understand the relationships among the physical characteristics of the loudspeaker. This paper focuses on the cone, the edge, and the behavior of air around the voice coil, which are important elements in the design of cone loudspeakers and evaluates their effects on the acoustic characteristics of the loudspeaker.

\section{Introduction}

People hear a variety of sounds in their everyday lives. Loudspeakers are designed for faithfully reproducing the original sound field. Currently, the most commonly used loudspeaker design is the cone loudspeaker. For faithful sound reproduction, the relationships among the physical characteristics of the loudspeaker must be elucidated. One of the physical characteristics required for an ideal loudspeaker, assuming a constant input voltage, is a flat sound pressure in the frequency domain.

In pursuit of this goal, researchers have long studied vibration analysis of the loudspeaker. Investigations of sound radiation by Brown [1] and Bordoni [2] treated the cone loudspeaker as a rigid body. However, the rigid body model of the cone is valid only during the so-called piston motion, in which the vibration system components, including the cone, edge, center cap, voice coil, and spider (see Figure 1), vibrate together as a unit in the low-frequency range. Nimura et al. [3] carried out a theoretical analysis of the vibration of the cone and used a graphical method to calculate the eigenvalues of the vibration of a conical loudspeaker cone. Kagawa [4] calculated the eigenvalues of the membrane vibrations of curved cones in addition to conical loudspeaker cones and found that curving the cone changed the eigenvalues of the membrane vibrations. Frankfort [5], also seeking solutions for the membrane vibrations of conical loudspeaker cones, formulated a differential equation that accounts for bending vibration and made detailed calculations of the sound pressure frequency response, vibration patterns, and driving-point admittance. However, Frankfort's analysis did not account for the effects of the edge and center cap, which play important roles in cone loudspeakers. Subsequently, the finite element method (FEM) has been used for vibration analysis of the cone [6-11]. Kyouno et al. analyzed the sound radiation from loudspeakers, accounting for coupling of the electrical, mechanical, and acoustic systems [12].

In these vibration analyses of cone loudspeakers, the cone maintains a piston motion in the low-frequency region. The biggest difficult point of these analyses is the split vibration of the vibration plate in the middle- and high-frequency regions. Control over the cone and the edge is very important in the design of a loudspeaker. However, there has been insufficient study of this topic in research up to now. 


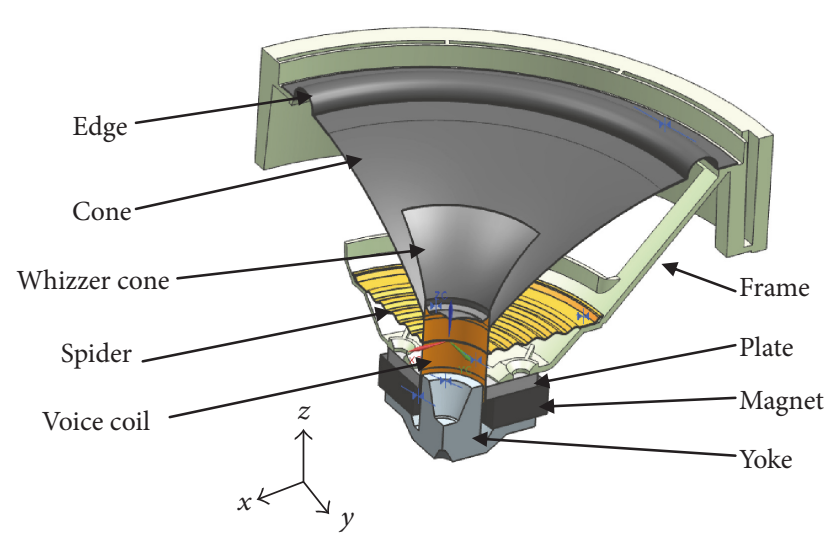

FIGURE 1: 1/4 model of a loudspeaker.

Furthermore, these acoustic analyses, particularly in the case of FEM, do not account for air viscosity, which may reduce the accuracy of their estimates of sound pressure frequency properties.

In particular, if the acoustic pathway in enclosure of small earphone is very narrow, air viscosity exerts a significant damping effect, reducing the estimation accuracy. Sasajima et al. succeeded at improving the estimation accuracy in the face of this problem by accounting for air viscosity using the finite element method [13].

Loudspeakers larger than earphones have a narrow space between the voice coil and the magnetic circuit, making it very likely that air viscosity has a significant impact and is a factor of estimation errors of the sound pressure frequency. Therefore, general acoustic analyses need to account for the damping effect of air viscosity to accurately analyze loudspeakers.

This paper examines cone loudspeakers, focusing intensively on the effects of the cone, the edge, and the narrow space between the voice coil and the magnetic circuit, which have a significant impact on the vibration characteristics and sound pressure frequency response. First, we perform an experimental study of the characteristics of a cone loudspeaker to determine its vibration characteristics and sound pressure frequency response. Next, we perform a vibrationacoustic analysis of the cone loudspeaker that accounts for the impact of air viscosity using our own independently developed acoustic analysis software. To verify the accuracy of our analysis, we compare the values from our analysis, which accounts for air viscosity, to the actual values of the vibration and sound pressure frequency properties. We also consider the behavior of the air around the voice coil. Finally, we calculate the optimal Young's modulus and density of the cone and edge and examine in detail their impact on the vibration characteristics.

\section{Methods and Materials}

Figure 1 illustrates the cone loudspeaker of diameter $0.16 \mathrm{~m}$, which is the focus of this study. Because the cone exhibits

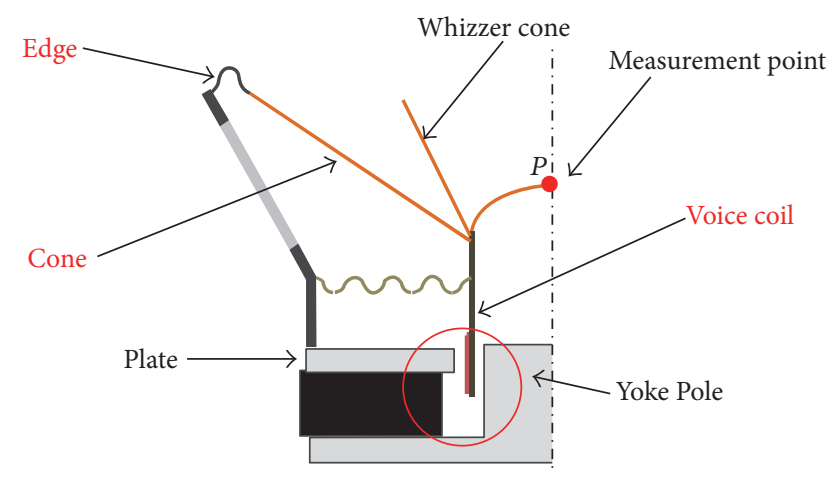

FIGURE 2: Important elements of the design of cone loudspeakers.

axial symmetry, we assume a model that is $1 / 4$ symmetric with respect to the $x-z$ and $y-z$ planes.

The defining feature of cone loudspeakers is that the cone is approximately conical in shape, as illustrated in Figure 1. The cone is supported by an edge around the outer periphery and a spider that supports the center of the cone by holding the voice coil in position. The outer perimeter of the spider is anchored to the frame. The cover at the center of the cone is typically a center cap, but our model used a whizzer cone to support the high-frequency characteristics.

The voice coil is attached to the center of the cone, where it is supplied with the input signal current. These elements comprise the loudspeaker's vibration system. The outer periphery of the vibration system is supported by a frame.

The magnetic circuit for supplying magnetic flux to the voice coil consists of a plate, magnet, and yoke. Magnetic flux is supplied by the magnet through the yoke [14]. Sound waves are generated when the driving force generated according to Fleming's left hand rule drives the cone, which is attached to the voice coil.

A cross-sectional view of the cone loudspeaker is shown in Figure 2. The performance of a loudspeaker is largely governed by its cone, which radiates the sound directly. In this sense, the cone can be said to be the heart of the loudspeaker. In an idealized model, the cone is always a rigid body travelling with a back-and-forth piston motion; however, in the middle- and high-frequency regions, the shape and material property values of the cone generate split vibrations in axisymmetric and nonaxisymmetric modes, exerting a significant influence on the loudspeaker's vibration characteristics and sound pressure frequency response.

The edge, by undergoing large deformations and acting as a spring, not only facilitates movement of the cone in the $z$-axis direction but also plays a role in reducing movement in the $x-y$ direction along the central axis. However, the edge does not always move back and forth together with the cone. The cone and the edge can vibrate in opposite phases, affecting the vibration characteristics.

By controlling the characteristics of the cone and edge, which are important design elements of a cone loudspeaker, the vibration characteristics of the cone loudspeaker can be improved. This study examines the vibration characteristics 


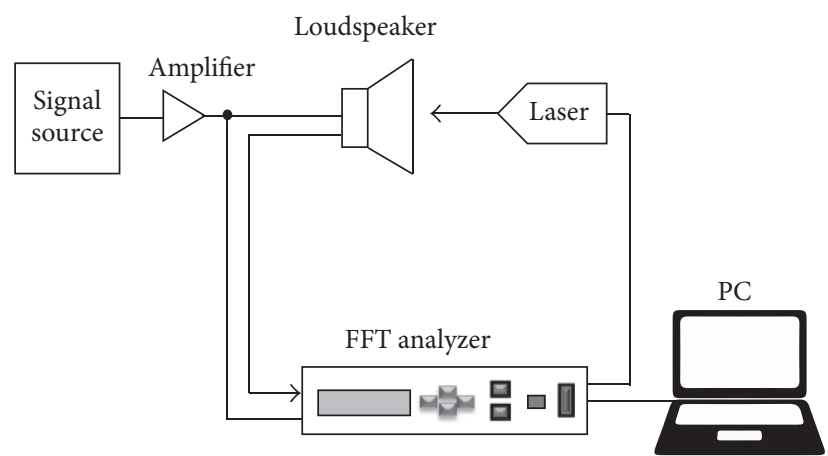

Figure 3: Cone vibration displacement measurement system.

of the loudspeaker by focusing attention on the materials of the cone and edge, which can be expected to have a particularly large impact.

In addition, the narrow space between the outer perimeter of the yoke pole and the inner perimeter of the plate, indicated in Figure 2, increases the air viscosity, and the flow of air in this gap can also be expected to have an important influence, which is very likely to be an error factor in the estimation of sound pressure frequency response. The damping effect of air viscosity, which is typically ignored in acoustic analysis, should therefore be taken into account for accurate analysis of loudspeaker performance.

\section{Experimental}

The performance of a cone loudspeaker is evaluated in terms of its vibration characteristics and sound pressure frequency properties; therefore, in our investigation, we took actual measurements of these characteristics.

3.1. Measurement of Cone Vibration Displacement. The cone is the core of a loudspeaker's vibration system, and it is therefore very important to understand the vibration characteristics of the cone when designing a loudspeaker's vibration system.

We measured the cone's vibration displacement using a laser displacement meter. Measurements were taken using a sweep signal of $10 \mathrm{~Hz}$ to $5 \mathrm{kHz}$, with the measurement point set to position $P$ at the center of the whizzer cone, which is located at the center of the loudspeaker cone (see Figure 2). The measurement system is shown in Figure 3.

Figure 4 shows the actual displacement characteristics at the measurement point. From $100 \mathrm{~Hz}$ to $800 \mathrm{~Hz}$, the displacement can be seen to decrease nearly linearly; however, beyond $800 \mathrm{~Hz}$, peaks occur at approximately 1 and $1.5 \mathrm{kHz}$.

\subsection{Measurement of Sound Pressure Frequency Properties.} We tested the sound pressure frequency of the loudspeaker by taking measurements in a reverberation room and an anechoic room, in accordance with the standards established in JIS Z 8732. Figure 5(a) shows a schematic of the two-room measurement environment, with the reverberation room on the left and the anechoic room on the right. Figure 5(b)

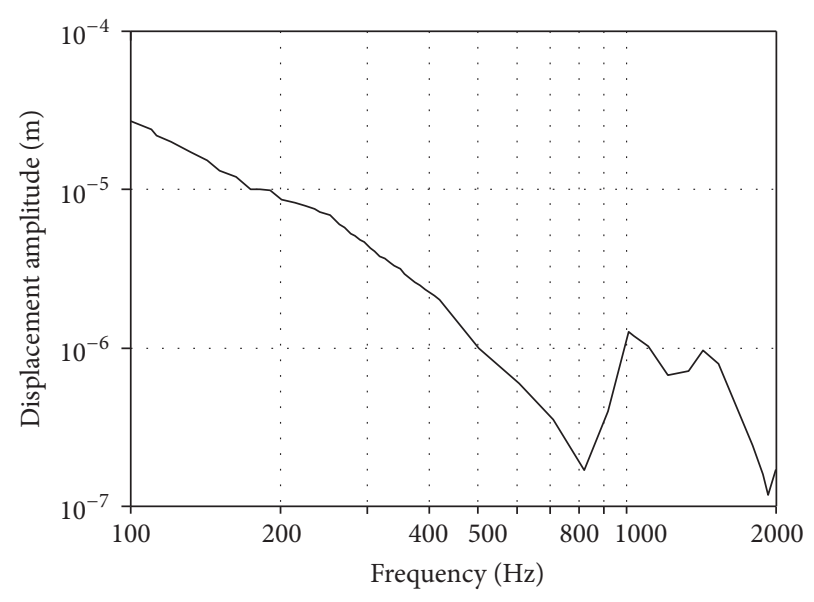

FIGURE 4: Comparison of the measurement result of cone vibration displacement amplitude.

shows a photo of the reverberation room and anechoic room as seen from the outside. The insides of the reverberation room and anechoic room are shown in Figures 5(c) and 5(d), respectively.

The measurement system included an audio analyzer (Etani Electronics ASA-10 Mark II) and a microphone (Aco type 4012). The tests were performed using a sweep signal in the frequency range of $20 \mathrm{~Hz}$ to $20 \mathrm{kHz}$. The observation point for measurement of the sound pressure in the anechoic room was a position $0.8 \mathrm{~m}$ in front of the loudspeaker, on its central axis. The measurement system is shown in Figure 6.

The measurement results are shown in Figure 7. An initial peak can be seen at approximately $80 \mathrm{~Hz}$, and then the sound pressure frequency characteristic is generally flat from $200 \mathrm{~Hz}$ to $1 \mathrm{kHz}$. Above $1 \mathrm{kHz}$, a pattern of repeated peaks and dips can be observed.

We were able to determine the acoustic characteristics of the cone loudspeaker from the results of the measurements of the cone vibration displacement and the sound pressure frequency properties.

However, these results by themselves do not reveal the impact of the cone and edge on the acoustic characteristics of the loudspeaker. This test was also inadequate in terms of the limited types of loudspeaker we were able to measure.

Therefore, to elucidate the effect of the materials of the cone and edge on the acoustic properties of the loudspeaker, we continued our investigation as follows. First, we performed a coupled analysis of vibration and acoustics, taking air viscosity into account. Next, we compared the results of the analysis to the experimental values to verify the accuracy of the analysis. In lieu of an experiment, we used the acoustic analysis to reproduce the effects of the characteristics of the cone and edge on the acoustic characteristics of the loudspeaker. Finally, we applied the response surface methodology to determine the optimal cone and edge materials in order to design a loudspeaker with the desired acoustic characteristics. 


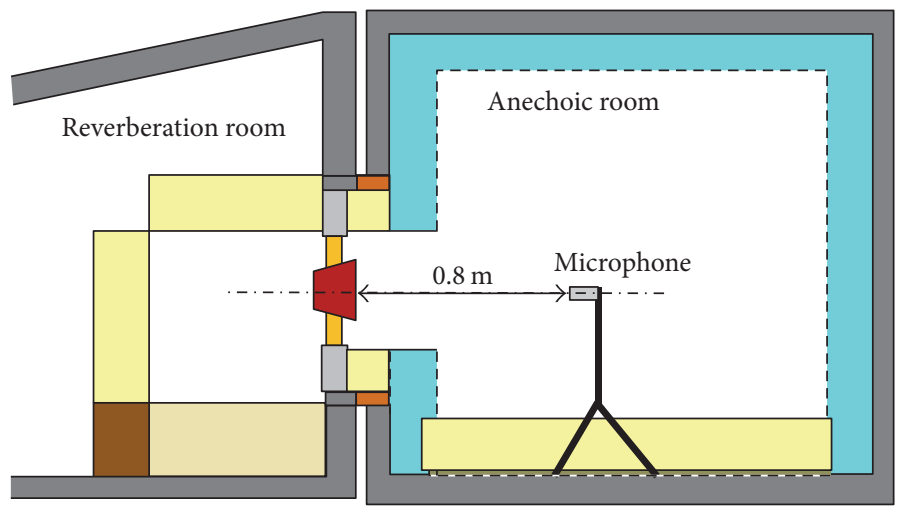

(a) Schematic of measurement environment

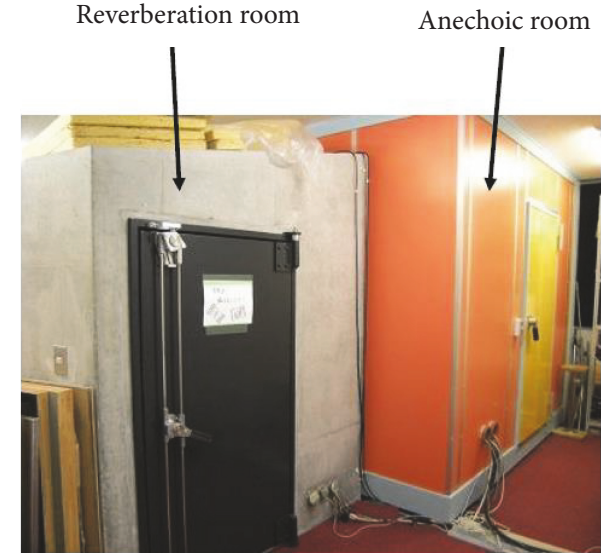

(b) Reverberation room and anechoic room

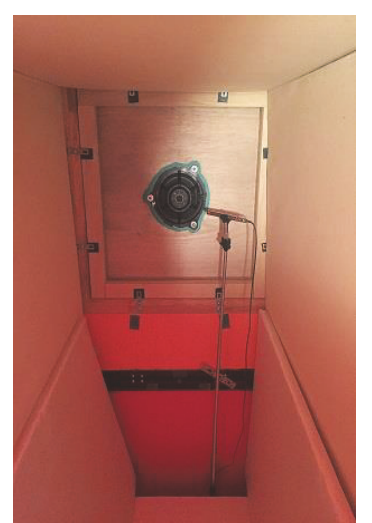

(c) Reverberation room

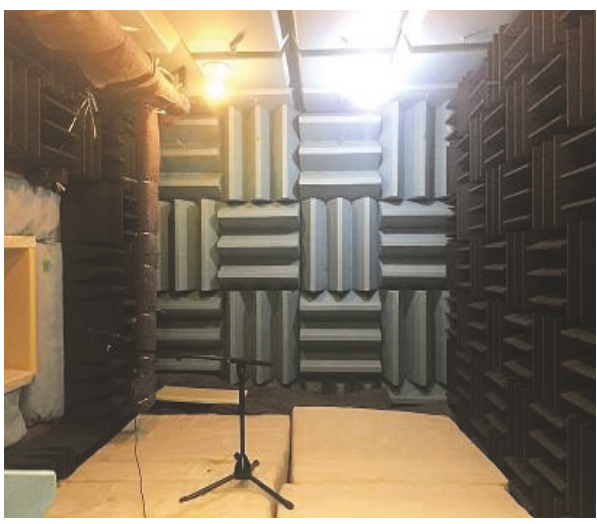

(d) Anechoic room

FIGURE 5: Measurement environment.

\section{Analysis and Results}

In order to account for air viscosity, which is typically ignored in acoustic analyses of cone loudspeakers, we propose an application of the finite element method to perform a coupled analysis of vibration and acoustics that takes into account air viscosity.

4.1. Method of Analysis. As the acoustic element, consider a three-dimensional tetrahedral element with unknown nodal displacements, as illustrated in Figure 8.

Letting $u_{x}, u_{y}$, and $u_{z}$ be the displacements in the $x, y$, and $z$ directions, respectively, at any point in the element, the strain energy $\widetilde{U}$ can be expressed as follows:

$$
\widetilde{U}=\frac{1}{2} E \iiint_{v_{e}}\left(\frac{\partial u_{x}}{\partial x}+\frac{\partial u_{y}}{\partial y}+\frac{\partial u_{z}}{\partial z}\right)^{2} d x d y d z
$$

Here, $E$ is the bulk modulus and $v_{e}$ is the volume of the tetrahedral element. Letting $\dot{u}$ be the time derivative of the displacement, the kinetic energy $\widetilde{T}$ is expressed as follows:

$$
\widetilde{T}=\frac{1}{2} \iiint_{v_{e}} \rho\{\dot{u}\}^{T}\{\dot{u}\} d x d y d z .
$$

Here, $\rho$ represents the density of the element, and $T$ represents the transposition. In addition, the viscous energy $\widetilde{D}$ of the viscous compressible fluid is expressed as follows:

$$
\widetilde{D}=\iiint_{v_{e}} \frac{1}{2}\left\{\bar{T}^{T}\right\} \Gamma d x d y d z
$$

Here, $\{\bar{T}\}$ is the stress vector due to viscosity, and $\Gamma$ is the strain vector.

Furthermore, using the potential energy $\widetilde{V}$ and applying Lagrange's equation, we obtain an equation of motion for the air elements that accounts for air viscosity:

$$
\frac{d}{d t} \frac{\partial \widetilde{T}}{\partial\left\{\dot{u}_{e}\right\}}-\frac{\partial \widetilde{T}}{\partial\left\{u_{e}\right\}}+\frac{\partial \widetilde{U}}{\partial\left\{u_{e}\right\}}-\frac{\partial \widetilde{V}}{\partial\left\{u_{e}\right\}}+\frac{\partial \widetilde{D}}{\partial\left\{\dot{u}_{e}\right\}}=0 .
$$

Here, $\left\{u_{e}\right\}$ and $\left\{\dot{u}_{e}\right\}$ are the nodal displacement vector and nodal velocity vector, respectively. Substituting (1)-(3) into (4), the following equation is obtained:

$$
-\omega^{2}\left[M_{e}\right]\left\{u_{e}\right\}+\left[K_{e}\right]\left\{u_{e}\right\}+\left[C_{e}\right]\left\{\dot{u}_{e}\right\}=\left\{f_{e}\right\} .
$$

Here, $\left[M_{e}\right],\left[K_{e}\right]$, and $\left[C_{e}\right]$ are the element mass matrix, the element stiffness matrix, and the element damping matrix, respectively. Furthermore, assuming a periodic 


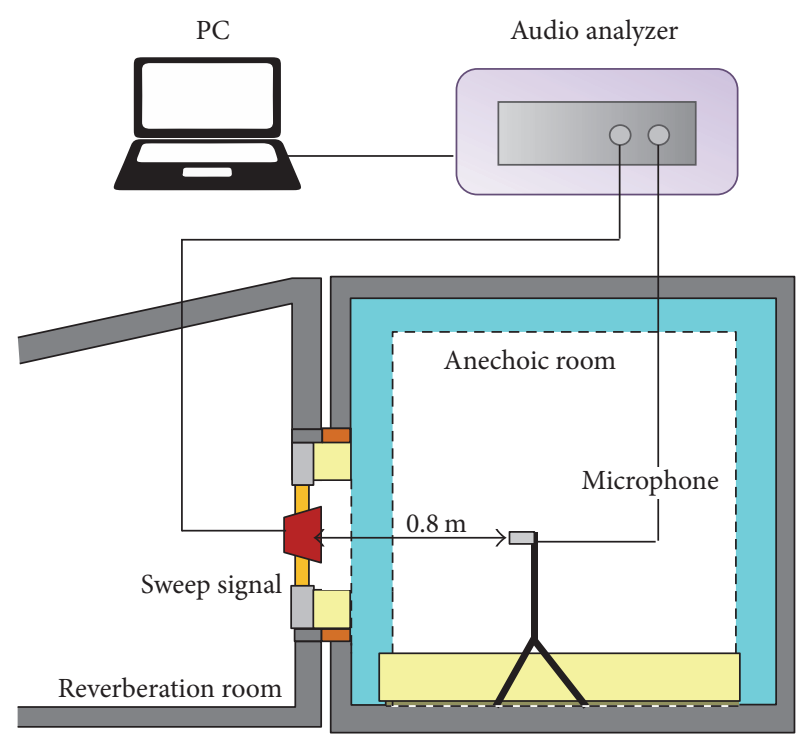

FigURE 6: Sound pressure frequency measurement system.

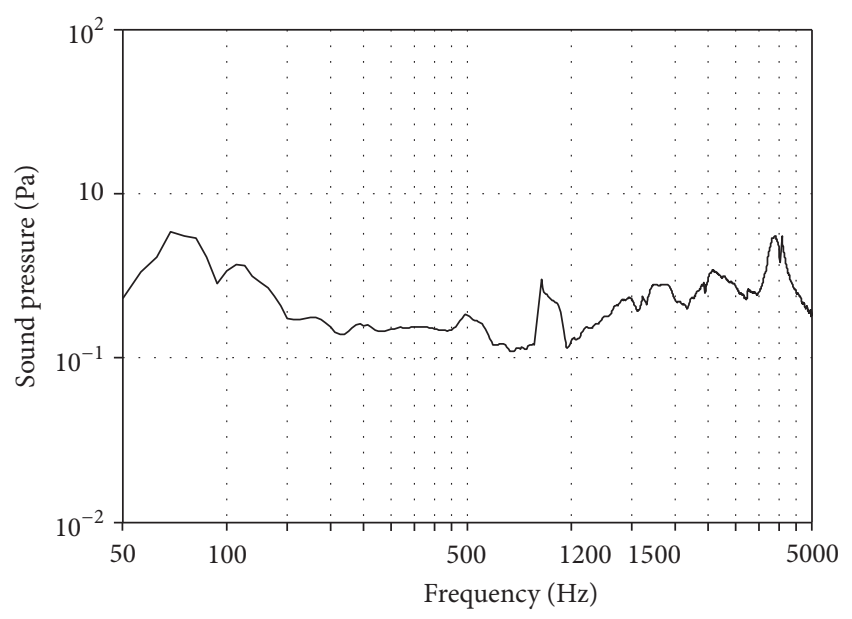

FIgURE 7: Comparison of measurement result and system characteristics of sound pressure frequency properties.

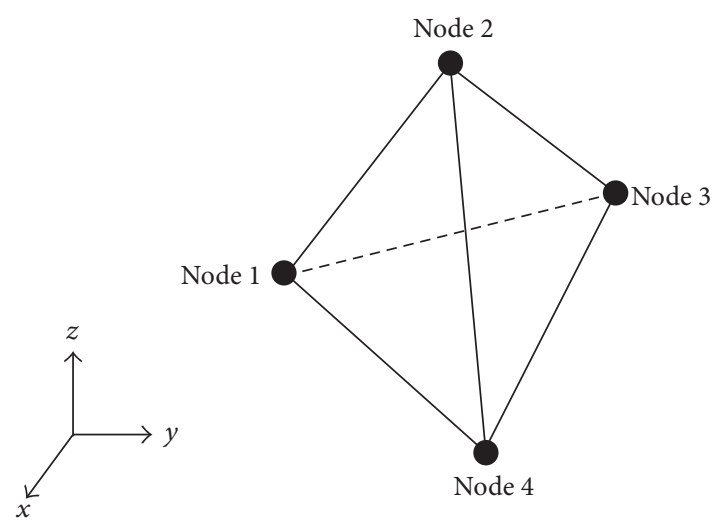

Figure 8: Tetrahedral element. response with an angular frequency of $\omega$ and using $\left\{\dot{u}_{e}\right\}=$ $j \omega\left\{u_{e}\right\},(5)$ can be expressed by the following equation:

$$
-\omega^{2}\left[M_{e}\right]\left\{u_{e}\right\}+\left[K_{e}\right]\left\{u_{e}\right\}+j \omega\left[C_{e}\right]\left\{u_{e}\right\}=\left\{f_{e}\right\} .
$$

Here, $-\omega^{2}\left[M_{e}\right]\left\{u_{e}\right\}$ is the inertia term, $\left[K_{e}\right]\left\{u_{e}\right\}$ is the stiffness term, $j \omega\left[C_{e}\right]\left\{u_{e}\right\}$ is the viscosity term, and $\left\{f_{e}\right\}$ is the external force.

For the structural elements, we use the general formulation:

$$
-\omega^{2}\left[M_{\mathrm{se}}\right]\left\{u_{\mathrm{se}}\right\}+\left[K_{\mathrm{se}}\right]\left\{u_{\mathrm{se}}\right\}=\left\{f_{\mathrm{se}}\right\},
$$

where $\left\{u_{\mathrm{se}}\right\},\left\{f_{\mathrm{se}}\right\},\left[K_{\mathrm{se}}\right]$, and $\left[M_{\mathrm{se}}\right]$ are the structural elements' nodal displacement vector, nodal force vector, complex stiffness matrix, and mass matrix, respectively. For the structural elements, in addition to tetrahedral elements, we also used hexahedral isoparametric elements account for incompatible modes.

Superimposing these equations of motion on the elements in the places of interest and letting the displacements be the common unknown variables, the following equation of motion for the entire system, including structure and acoustics, is obtained:

$$
-\omega^{2}[M]\{u\}+[K]\{u\}+j \omega[C]\{u\}=\{f\} .
$$

By solving the equation of motion in (8) for displacement, all nodal displacements can be determined. Furthermore, the strain and pressure of each element can be calculated from the nodal displacements [13].

Therefore, we used solutions of (8) to carry out the coupled vibration and acoustic analysis described in this paper.

To verify the performance of the loudspeaker, we relied primarily on frequency response analysis. To calculate the pressure of the elements during the actual vibration and acoustic analysis, we divided up the frequency range to be analyzed and then found the nodal displacement $\{u\}$ corresponding to the sine wave excitation force $\{f\}$ at each frequency. By repeating these calculations, the nodal displacement and element pressure were calculated for the entire frequency range to be analyzed, yielding frequency response characteristic graphs for displacement and pressure.

4.2. Analytical Model. We created an analytical model with conditions substantially equivalent to the conditions in the reverberation room and anechoic room shown in Figure 5. As illustrated in Figure 9(b), the analytical model is composed of three parts: the sound-absorbing elements in the outer pink areas, the air elements in the inner green areas, and the cone loudspeaker setup in the airspace in the small reverberation room. Figure 9(a) shows the element model of the loudspeaker from the middle of Figure 9(b).

Within the loudspeaker elements, there is a narrow width of only $2 \times 10^{-5} \mathrm{~m}$ between the voice coil and the magnetic circuit. In order to determine the behavior of the air around the voice coil in a way that accounts for the viscosity of the air, the fine air mesh shown in Figure 9(c) was created. For 


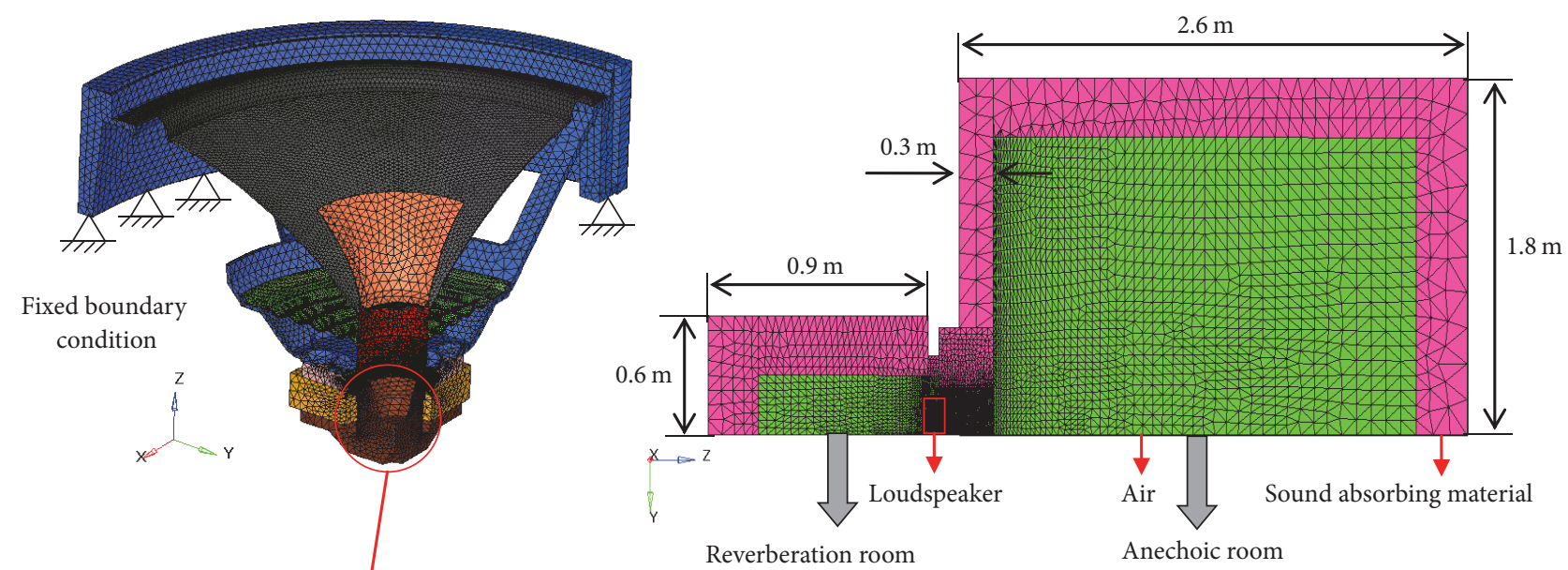

(b) All analytical models

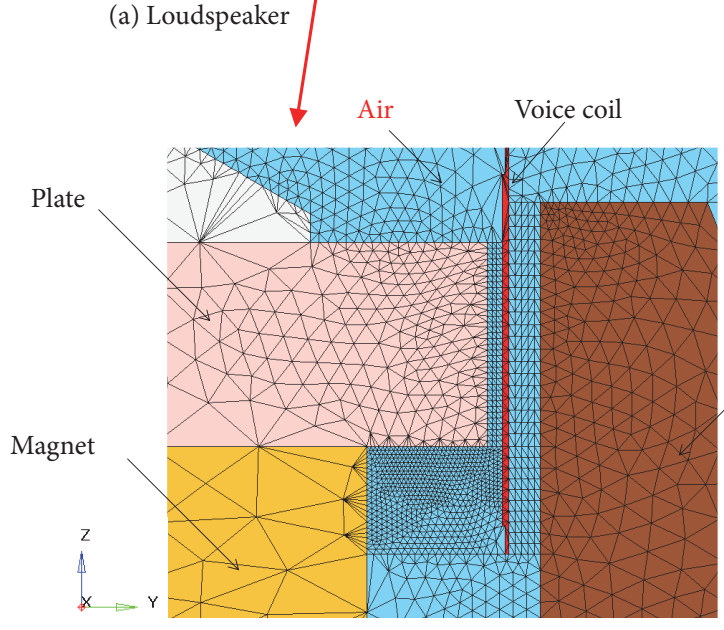

(c) Air between voice coil and magnetic circuit

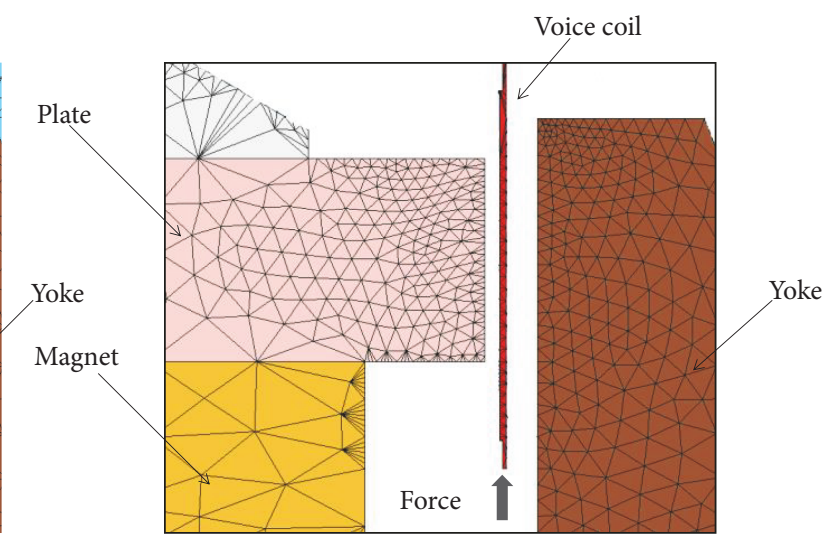

(d) No air between voice coil and magnetic circuit

FIGURE 9: Analytical model.

comparison, Figure 9(d) shows the state when there is no air between the voice coil and magnetic circuit.

As a result, the structural part of the model contained 159,042 elements and 42,965 nodes, while the air part contained 704,942 elements and 143,585 nodes.

The sine wave excitation force $F$ was applied to the entire circumference of the voice coil in the direction of the center axis of the loudspeaker, as shown in Figure 9(d).

With respect to the boundary conditions, the three degrees of freedom on the $x$-, $y$-, and $z$-axes were fixed at the underside of the frame as shown in Figure 9 (a) and at the exterior air nodes as shown in Figure 9(b). In addition, to account for symmetry conditions, the displacement of nodes on the $y-z$ and $x-z$ planes was fixed in the $x$-axis and $y$-axis directions, respectively.

Since the loudspeaker is made of composite materials, the material properties used in our analysis were measured by the vibrating reed method [15] for the cone and whizzer cone, by the tensile test for the edge, and by FEM static analysis based on load displacement measurements for the spider. Other physical property values were obtained by consulting chronological scientific tables. Table 1 shows the actual physical property data used in our analysis. Other physical property values included an effective air density of $1.2 \mathrm{~kg} / \mathrm{m}^{3}$, a bulk modulus of $1.4 \times 10^{5} \mathrm{~N} / \mathrm{m}^{2}$, a coefficient of viscosity of $1.82 \times 10^{-5} \mathrm{~N} \cdot \mathrm{s} / \mathrm{m}^{2}$, and a speed of sound of $340.0 \mathrm{~m} / \mathrm{s}$.

4.3. Verification of the Accuracy of Our Analysis of Cone Vibration Displacement. Figure 10 shows a comparison of the cone vibration displacement amplitudes from the measurement results and analysis results. The solid line represents the measurement results, and the dashed line represents the results calculated by considering air viscosity.

The results in Figure 10 show that the values from our analysis are in good agreement with the actual measured values. The fact that our calculation results yield roughly the same characteristics as the actual measured cone vibration displacement values suggests that highly accurate vibration analysis results can be obtained accounting for air viscosity. Pressure Frequency Properties. Figure 11 compares the results 
TABLE 1: Material and geometric parameters.

\begin{tabular}{lccc}
\hline Parts & $\begin{array}{c}\text { Mass density } \\
\left(\mathrm{kg} / \mathrm{m}^{3}\right)\end{array}$ & $\begin{array}{c}\text { Young's modulus } \\
\left(\mathrm{N} / \mathrm{m}^{2}\right)\end{array}$ & $\begin{array}{c}\text { Poisson's } \\
\text { ratio }\end{array}$ \\
\hline Cone & $3.1 \times 10^{2}$ & $1.16 \times 10^{9}$ & 0.3 \\
Edge & $8.0 \times 10^{2}$ & $1.39 \times 10^{8}$ & 0.3 \\
Spider & $6.60 \times 10^{2}$ & $8.90 \times 10^{7}$ & 0.3 \\
Whizzer cone & $5.70 \times 10^{2}$ & $2.00 \times 10^{9}$ & 0.3 \\
Voice coil & $1.87 \times 10^{3}$ & $1.29 \times 10^{11}$ & 0.34 \\
Magnet & $4.80 \times 10^{3}$ & $1.18 \times 10^{11}$ & 0.3 \\
Plate & $7.69 \times 10^{3}$ & $2.00 \times 10^{11}$ & 0.3 \\
Yoke & $7.94 \times 10^{3}$ & $2.00 \times 10^{11}$ & 0.3 \\
Frame & $9.10 \times 10^{2}$ & $1.66 \times 10^{9}$ & 0.3 \\
\hline
\end{tabular}

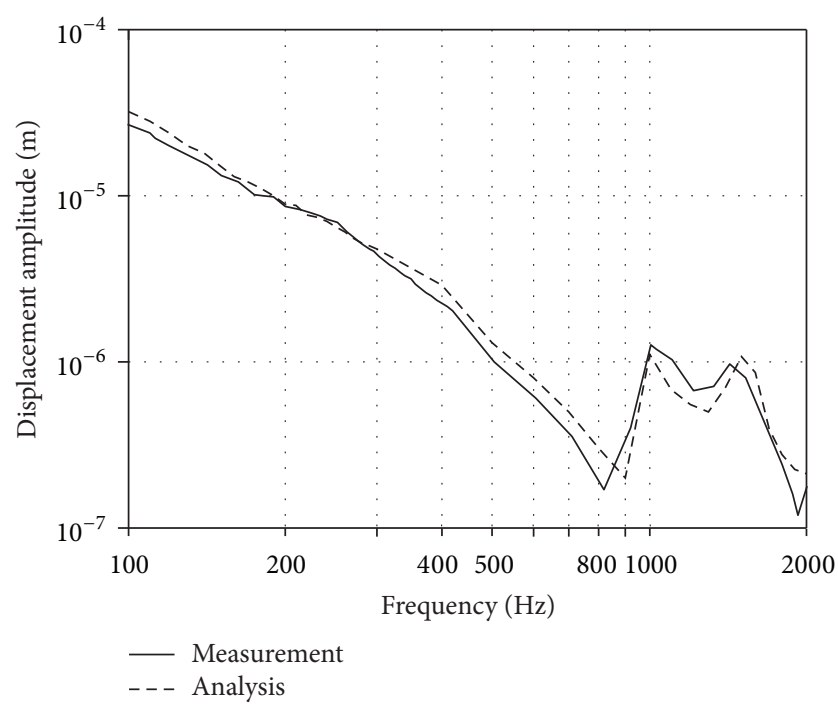

FIGURE 10: Comparison of the measurement result and analysis with viscosity of cone vibration displacement amplitude.

of our calculation of the sound pressure frequency response in the direction of the axis of the loudspeaker to the actual measurement results from the sweep signal excitation. The solid line represents the measurement results, and the dashed line represents the results calculated by considering air viscosity.

The changes and characteristics of the sound pressure frequency response from our analysis results are consistent with the traditional view in the literature that more accurate characteristics can be obtained by analyses that account for the viscous damping of the air [16].

The reason for this is that the narrow space between the voice coil and the magnetic circuit is so narrow that the air viscosity in the space affects the up-and-down motion of the voice coil. Our analysis is able to account for rotation as well as translational motion of air elements along the $x$-, $y$-, and $z$ axes. It is therefore able to represent the behavior of the air in the narrow passage, yielding calculation results that are closer to the actual measured values.

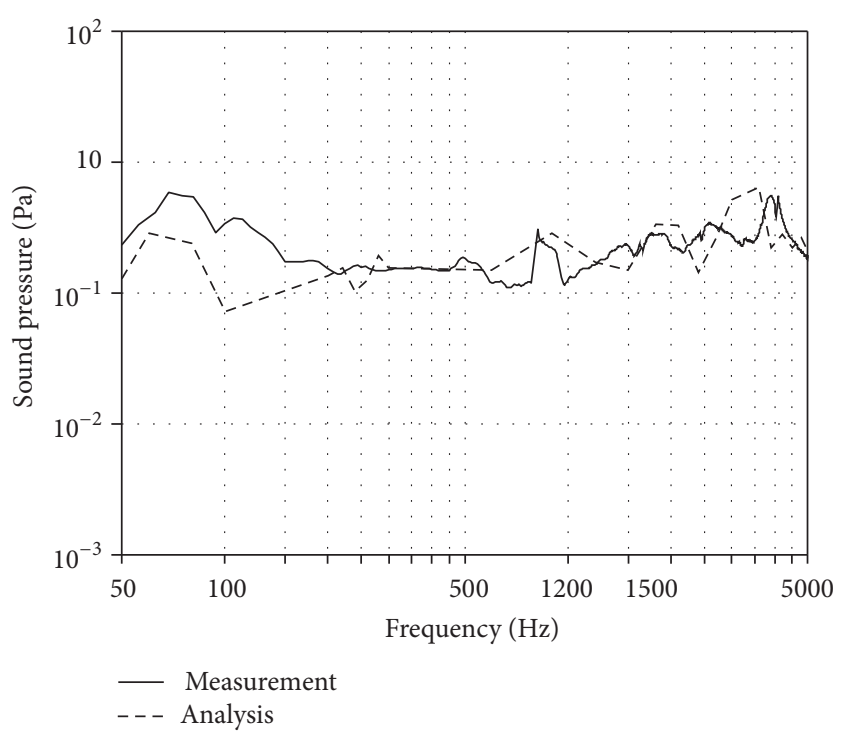

FIGURE 11: Comparison of measurement result and characteristics measurement system pressure frequency characteristics.

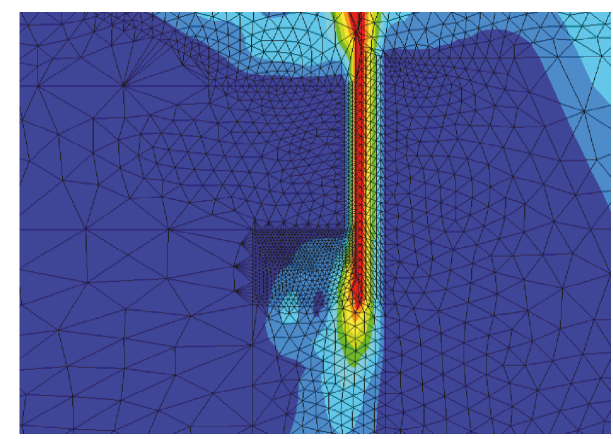

(a) Vibration mode around the voice coil

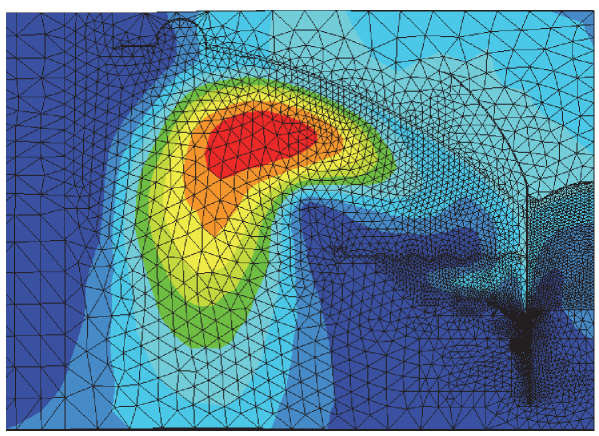

(b) Vibration mode around the cone

FIGURE 12: Effect by vibration mode of air with viscosity.

4.5. Impact of the Narrow Space between the Voice Coil and the Magnetic Circuit. When designing a cone loudspeaker, it is very important to consider the behavior of the air between the circumference of the voice coil and the magnetic circuit.

Figure 12(a) shows the behavior of the air around the voice coil when air viscosity is taken into account. Red indicates areas of large displacement and blue indicates areas of small 


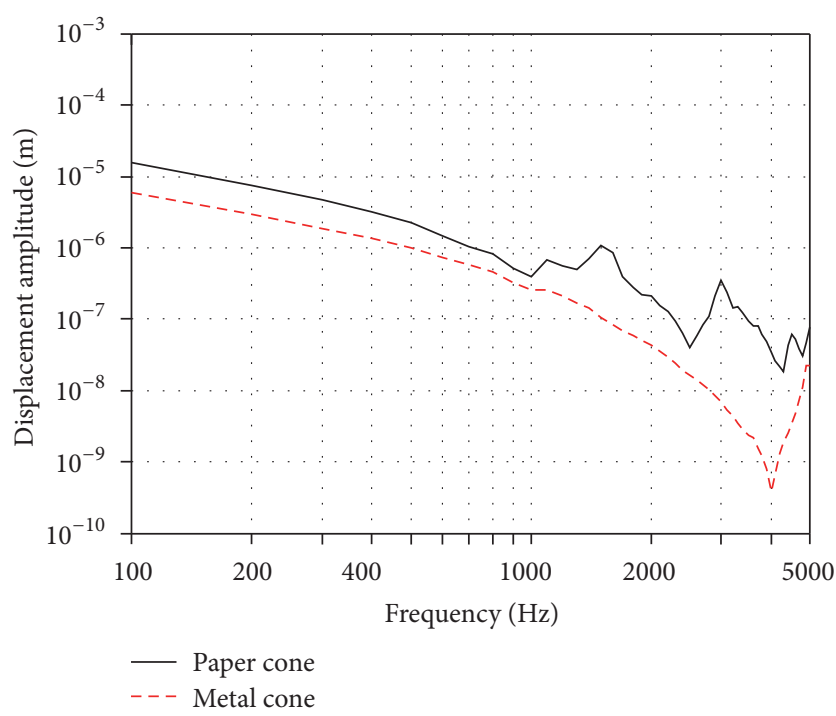

FIGURE 13: Comparison vibration characteristic of metal cone and paper cone.

displacement. When air viscosity is taken into account, the differences in air pressure become apparent, and, owing to the natural tendency of air to flow from areas of high pressure to areas of low pressure, the direction of the air flow from the vibration of the voice coil becomes apparent. Figure 12(b) shows the behavior of the air around the cone. The figure clearly shows the direction of the air flow around the cone due to the behavior of the air around the voice coil.

The analysis results shown in Figure 12 demonstrate the potential for consciously designing the fine-grained characteristics of a loudspeaker by adjusting parameters such as the viscous resistance of the narrow acoustic pathway between the voice coil and magnetic circuit.

Using this analysis method, which accounts for air viscosity, it is possible to visualize the movement of air and capture the behavior of the air around the voice coil by solving the equation of motion with the nodal displacements as unknown quantities.

4.6. Impact of the Cone on the Acoustic Characteristics of the Loudspeaker. For purposes of comparison, we investigated cones made of both metal and paper-based materials. When metal is used, the material is highly uniform and exhibits greater flexural rigidity at the same thickness. On the other hand, when paper-based materials are used, the cone is easier to manufacture, but its vibration characteristics are likely to be more complicated because its flexural rigidity is lower than that of metal and the random arrangement of the pulp fibers renders the material nonuniform.

Figure 13 shows the cone displacement responses calculated by this method, accounting for air viscosity. The solid and dashed lines show the displacement responses for the metal and paper cones, respectively.

The figure shows that the metal cone exhibits piston motion up to $5 \mathrm{kHz}$, with virtually no peaks and dips in

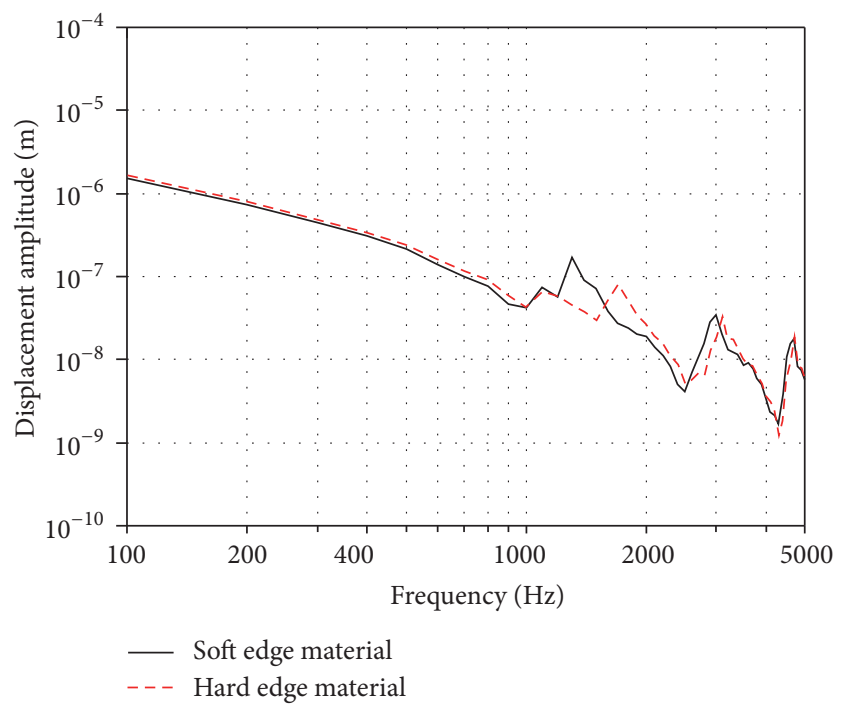

FIGURE 14: Comparison vibration characteristic of soft edge and hard edge material.

displacement. In the case of the paper cone, more dips and peaks are observed, because the cone is softer and more prone to split vibration, in which the motion of the voice coil is not transmitted to the entire cone.

4.7. Impact of the Edge on the Acoustic Characteristics of the Loudspeaker. We compared the performance of an edge made of a soft material with Young's modulus of $6.95 \times$ $10^{7} \mathrm{~N} / \mathrm{m}^{2}$ and an edge made of a hard material with Young's modulus of $2.78 \times 10^{8} \mathrm{~N} / \mathrm{m}^{2}$. Figure 14 shows the vibration characteristics calculated by this method, taking into account air viscosity. The solid and dashed lines show the displacement response for the soft and hard materials, respectively.

The results in the figure show an initial peak at $1.3 \mathrm{kHz}$ in the case of the soft edge material and an initial peak at $1.7 \mathrm{kHz}$ in the case of the hard edge material. In other words, we used our analysis method to perform a coupled analysis of vibration and acoustics in which only the edge material was changed not the shape of the cone. These results demonstrate the potential for consciously designing the finegrained characteristics of a loudspeaker, such as the first-peak position.

\section{Discussion}

In the previous sections of this paper, we took into account the viscosity of the air, verified the accuracy of the coupled analysis of vibration and acoustics of the loudspeaker, and saw the impact of the material of the cone and edge on the acoustic characteristics of the loudspeaker. Extending this line of research, a significant remaining challenge is to design the appropriate cone and edge characteristics to obtain the desired acoustic characteristics in the loudspeaker. 


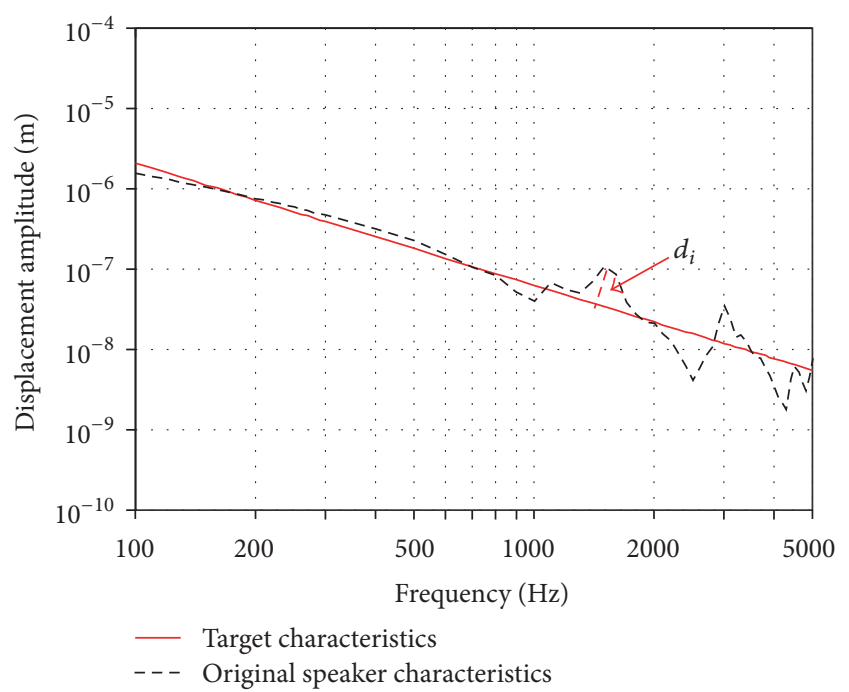

FIGURE 15: Cone vibration displacement amplitude standard analysis result and objective function.

To address this challenge, in this section, we consider how to optimize the cone and edge, expressing the problem mathematically as follows:

$$
\begin{array}{ll}
\text { Find } & x=\left[\rho_{c}, E_{c}, \rho_{e}, E_{e}\right]^{T} \\
\min & W=f(x)=\sqrt{\sum_{i=1}^{n} d_{i}^{2}} \quad(i=1,2, \ldots, n) \\
\text { S.t. } & 100\left[\mathrm{~kg} / \mathrm{m}^{3}\right] \leq \rho_{c} \leq 1200\left[\mathrm{~kg} / \mathrm{m}^{3}\right] \\
& 7.3 \times 10^{8}\left[\mathrm{~N} / \mathrm{m}^{2}\right] \leq E_{c} \leq 70 \times 10^{8}\left[\mathrm{~N} / \mathrm{m}^{2}\right] \\
& 300\left[\mathrm{~kg} / \mathrm{m}^{3}\right] \leq \rho_{e} \leq 1300\left[\mathrm{~kg} / \mathrm{m}^{3}\right] \\
& 3.2 \times 10^{7}\left[\mathrm{~N} / \mathrm{m}^{2}\right] \leq E_{e} \leq 20 \times 10^{7}\left[\mathrm{~N} / \mathrm{m}^{2}\right] .
\end{array}
$$

Here, $\rho_{c}$ is the density of the cone, $E_{c}$ is Young's modulus of the cone, $\rho_{e}$ is the density of the edge, $E_{e}$ is Young's modulus of the edge, and $W=f(x)$ is the objective function of optimization. In Figure 15, the solid line represents the target characteristic value, the dashed line (which was previously shown in Figure 10) represents the cone vibration displacement characteristics from our analysis, and $d_{i}(i=1,2, \ldots, n)$ represents the distance from the displacement characteristic to the target characteristic value at each frequency from 1 to $5 \mathrm{kHz}$. The number of sampling points was set to $n=50$.

Although paper-based materials, metal materials, and other materials have been used to construct the soundradiating cones in loudspeakers, paper-based materials are used most often. For that reason, the constraints imposed on the ranges of the cone's density and Young's modulus in (9) were set in the ranges for paper-based materials. Similarly,

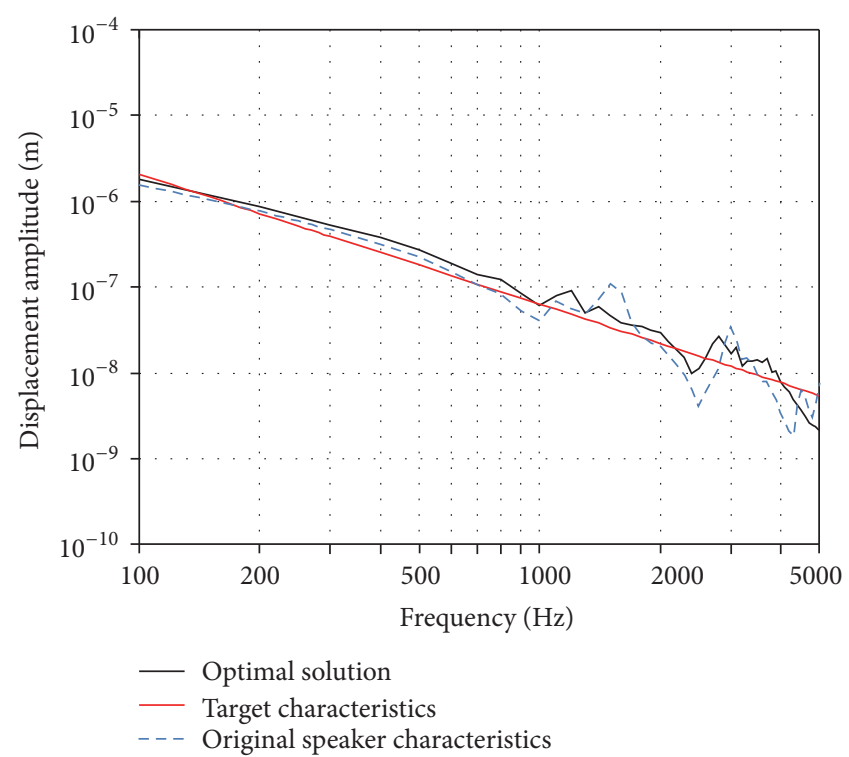

FIGURE 16: Analysis result of optimal solution.

the range of values established for the edge in (9) reflects the fact that the edge is typically constructed using cotton fabric and rubber.

We used the response surface methodology to optimize the physical properties of the cone and edge by carrying out the following calculation steps. First, we generated sample data in order to create the response surface for the optimization. Next, using the sample data, we carried out vibration analysis of the loudspeaker by changing the physical properties of each of its parts and, based on the results of the analysis, extracted the objective function values for the optimization calculation. Finally, we established a one-to-one correspondence between sample data and the characteristic values, created an interpolation approximation formula by the response surface method, and then used the approximation formula to find the optimum solution by performing the optimization calculation [17, 18].

Table 2 shows the sample data that was generated using the design variables and their upper and lower limit values, as well as the objective function value $d$, which is the result obtained from the coupled analysis of vibration and acoustics in accordance with the sample data.

We used these results to create the response surface and perform the optimization, the results of which are shown in Table 3.

Figure 16 shows the results of the vibration analysis using the optimal solution that was obtained. The black solid line represents the analysis result for the optimal solution and the red solid line represents the target characteristic values. The dashed line represents analysis results for the original loudspeaker shown in Figure 10. The results obtained for the optimal solution closely match the target characteristic values.

The optimal solution exhibits flatter characteristics compared to the original cone vibration displacement characteristics, which exhibited peaks at 1.5 and $3 \mathrm{kHz}$ and a dip at 
TABLE 2: Sample data and analysis results.

\begin{tabular}{|c|c|c|c|c|c|}
\hline Number & $\begin{array}{c}\text { Cone } \\
\text { mass density } \\
\left(\mathrm{kg} / \mathrm{m}^{3}\right)\end{array}$ & $\begin{array}{c}\text { Cone } \\
\text { Young's } \\
\text { modulus } \\
\left(10^{8} \mathrm{~N} / \mathrm{m}^{2}\right)\end{array}$ & $\begin{array}{c}\text { Edge } \\
\text { mass density } \\
\left(\mathrm{kg} / \mathrm{m}^{3}\right)\end{array}$ & $\begin{array}{c}\text { Edge } \\
\text { Young's } \\
\text { modulus } \\
\left(10^{7} \mathrm{~N} / \mathrm{m}^{2}\right)\end{array}$ & $\begin{array}{c}\text { Analysis result } \\
d\end{array}$ \\
\hline 1 & 100 & 7.3 & 300 & 3.2 & 0.35 \\
\hline 2 & 100 & 7.3 & 300 & 12 & 0.33 \\
\hline 3 & 100 & 7.3 & 300 & 20 & 0.31 \\
\hline 4 & 650 & 7.3 & 800 & 3.2 & 0.51 \\
\hline 5 & 650 & 7.3 & 800 & 12 & 0.60 \\
\hline 6 & 650 & 7.3 & 800 & 20 & 0.56 \\
\hline 7 & 1200 & 7.3 & 1300 & 3.2 & 0.67 \\
\hline 8 & 1200 & 7.3 & 1300 & 12 & 0.61 \\
\hline 9 & 1200 & 7.3 & 1300 & 20 & 0.68 \\
\hline 10 & 100 & 39 & 800 & 3.2 & 1.06 \\
\hline 11 & 100 & 39 & 800 & 12 & 1.03 \\
\hline 12 & 100 & 39 & 800 & 20 & 1.02 \\
\hline 13 & 650 & 39 & 1300 & 3.2 & 1.29 \\
\hline 14 & 650 & 39 & 1300 & 12 & 1.25 \\
\hline 15 & 650 & 39 & 1300 & 20 & 1.27 \\
\hline 16 & 1200 & 39 & 300 & 3.2 & 1.46 \\
\hline 17 & 1200 & 39 & 300 & 12 & 1.43 \\
\hline 18 & 1200 & 39 & 300 & 20 & 1.44 \\
\hline 19 & 100 & 70 & 1300 & 3.2 & 0.98 \\
\hline 20 & 100 & 70 & 1300 & 12 & 1.01 \\
\hline 21 & 100 & 70 & 1300 & 20 & 1.00 \\
\hline 22 & 650 & 70 & 300 & 3.2 & 1.55 \\
\hline 23 & 650 & 70 & 300 & 12 & 1.56 \\
\hline 24 & 650 & 70 & 300 & 20 & 1.55 \\
\hline 25 & 1200 & 70 & 800 & 3.2 & 1.74 \\
\hline 26 & 1200 & 70 & 800 & 12 & 1.77 \\
\hline 27 & 1200 & 70 & 800 & 20 & 1.79 \\
\hline
\end{tabular}

TABLE 3: Design variables of optimization.

\begin{tabular}{lcc}
\hline & Initial value & Optimal value \\
\hline$\rho_{c}\left(\mathrm{~kg} / \mathrm{m}^{3}\right)$ & 650 & 100 \\
$E_{c}\left(\mathrm{~N} / \mathrm{m}^{2}\right)$ & $39 \times 10^{8}$ & $28 \times 10^{8}$ \\
$\rho_{e}\left(\mathrm{~kg} / \mathrm{m}^{3}\right)$ & 800 & 800 \\
$E_{e}\left(\mathrm{~N} / \mathrm{m}^{2}\right)$ & $12 \times 10^{7}$ & $20 \times 10^{7}$ \\
\hline
\end{tabular}

$2.5 \mathrm{kHz}$. The characteristics also appear flatter over the entire frequency range. The result of the objective function value $d$ for the optimal solution was $d=0.26$, which represents an improvement of approximately 35\% over the original loudspeaker, for which the result was $d=0.40$.

In the optimal solution, the density of the cone was $100 \mathrm{~kg} / \mathrm{m}^{3}$, and Young's modulus was $28 \times 10^{8} \mathrm{~N} / \mathrm{m}^{2}$. These properties define a cone that is lighter in weight and vibrates more easily but whose stiffness enables suppression of split vibration in the nonaxisymmetric mode. This suggests that cones should be constructed from light but rigid materials.
The results for the edge were a density of $800 \mathrm{~kg} / \mathrm{m}^{3}$ and Young's modulus of $20 \times 10^{7} \mathrm{~N} / \mathrm{m}^{2}$. Since the edge supports the cone, this suggests that edges should be constructed of materials with high rigidity.

In addition, the vibration mode of the cone was examined. The vibration modes of the cones are shown in Figure 17. Red and blue indicate areas of large and small displacement, respectively. Figure 17 (a) shows the vibration mode of a standard loudspeaker cone at $1.5 \mathrm{kHz}$, and Figure 17(b) shows the vibration displacement mode of an optimal cone at $1.5 \mathrm{kHz}$. In the case of the standard loudspeaker, it can be seen that the displacement is smaller at the center of the cone and greater at the periphery (the part attached to the edge), whereas the optimal cone moves with the same amount of displacement.

By changing Young's modulus and density of the cone and edge, we were able to reduce the peaks that occur due to split vibration of the cone in the middle- and highfrequency regions above $1 \mathrm{kHz}$ and achieve flatter frequency characteristics. 


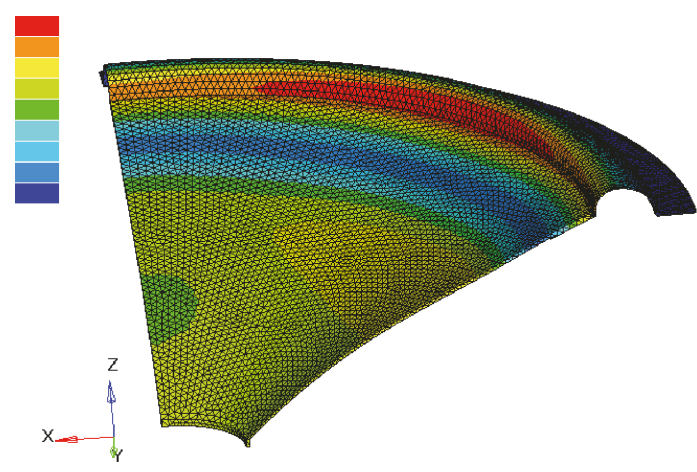

(a) Vibration mode of the standard cone

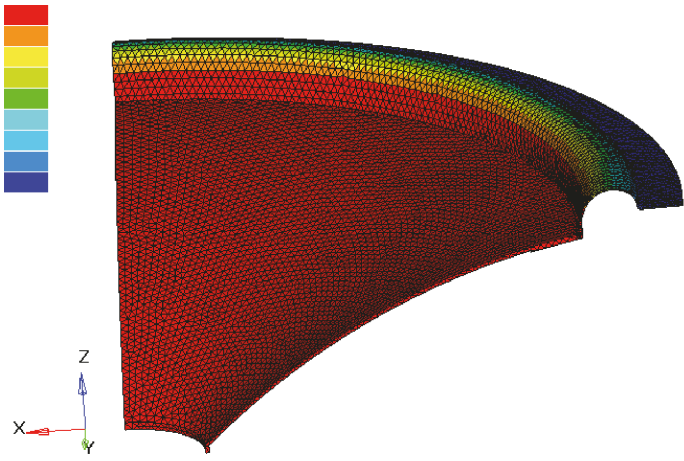

(b) Vibration mode of the optimal cone

Figure 17: Analysis result of optimal solution: cone A at $1500 \mathrm{~Hz}$.

\section{Conclusion}

This study focused on the cone, the edge, and the behavior of air around the voice coil, which are important elements in the design of cone loudspeakers, and evaluated their effects on the acoustic characteristics of a loudspeaker. We performed a coupled analysis of the vibration and acoustics of a cone loudspeaker that accounted for the impact of air viscosity, which has received little attention in traditional acoustic analyses, and then sought optimal materials for the cone and edge. The following results were obtained:

(1) We took measurements of the vibration characteristics and sound pressure frequency response of a cone loudspeaker in order to determine its acoustic characteristics.

(2) We performed a coupled analysis of the vibration and acoustics of the loudspeaker that accounted for air viscosity and compared the vibration characteristics and sound pressure frequency response to the actual measured values. By accounting for air viscosity, the analysis was able to yield high accuracy.

(3) The coupled analysis of vibration and acoustics revealed the vibration characteristics of the cone, which are influenced by the characteristics of the cone and edge. Furthermore, with respect to the behavior of the air around the voice coil in the loudspeaker, the results of our analysis, which accounted for air viscosity, enabled us to clearly see the direction of air movement; this is not possible with traditional analyses. This led to an improvement in the accuracy of the analysis.

(4) We used the response surface methodology to optimize the design of Young's modulus and density of the cone and edge and obtained the optimum physical properties of the cone and edge in order to design a loudspeaker with the desired acoustic characteristics. The optimal solution that was obtained reduced the peaks and dips caused by split vibration of the cone and achieved flatter vibration characteristics.
With respect to future challenges, we hope to investigate the analysis of loudspeakers of complex shapes, beyond typical cone loudspeakers. In addition, we would like to alter the shape of the loudspeaker components in ways that will lead to an optimum design to achieve flatter sound pressure frequency properties.

\section{Conflicts of Interest}

The authors declare that there are no conflicts of interest regarding the publication of this paper.

\section{References}

[1] W. N. Brown, “Theory of conical sound radiators," Journal of the Acoustical Society of America, vol. 13, no. 1, pp. 20-22, 1941.

[2] P. G. Bordoni, "The conical sound source," The Journal of the Acoustical Society of America, vol. 28, no. 2, pp. 123-126, 1945.

[3] T. Nimura, E. Matsui, K. Shibayama, and K. Kido, "Study on the cone type dynamic loudspeakers," The Journal of the Acoustical Society of Japan, vol. 7, no. 2, pp. 16-28, 1952.

[4] Y. Kagawa, "Natural frequency and vibration modes of curved cone extensional vibration," Tohoku University Dentsu Discourse Record, vol. 31, no. 3, 1962.

[5] F. J. Frankfort, Vibration and sound radiation of loudspeaker cones [thesis], Philips Research Reports Supplements no 2, 1975.

[6] T. Ueno, K. Takahashi, K. Ichida, and S. Ishii, "The vibration analysis of a cone loudspeaker by the finite element method," The Journal of the Acoustical Society of Japan, vol. 34, no. 8, pp. 470-477, 1978.

[7] K. Suzuki and I. Nomoto, "Computerized analysis and observation of the vibration modes of a loudspeaker cone," Journal of the Audio Engineering Society, vol. 30, no. 3, pp. 98-106, 1982.

[8] A. J. M. Kaizer, "Modeling of the nonlinear response of an electrodynamic loudspeaker by a volterra series expansion," AES: Journal of the Audio Engineering Society, vol. 35, no. 6, pp. 421-433, 1987.

[9] A. J. M. Kaizer, "Calculation of the sound radiation of a nonrigid loudspeaker diaphragm using the finite-element method," Journal of the Audio Engineering Society, vol. 36, no. 7-8, pp. 539-551, 1988. 
[10] E. B. Skrodzka and A. P. Sęk, "Comparison of modal parameters of loudspeakers in different working conditions," Applied Acoustics, vol. 60, no. 3, pp. 267-277, 2000.

[11] R. M. Aarts, "Optimally sensitive and efficient compact loudspeakers," Journal of the Acoustical Society of America, vol. 119, no. 2, pp. 890-896, 2006.

[12] N. Kyouno, T. Usagawa, T. Yamabuchi, and Y. Kagawa, "Acoustic response analysis of a cone-type loudspeaker by the finite element method," The Journal of the Acoustical Society of Japan, vol. 61, no. 6, pp. 312-319, 2005.

[13] M. Sasajima, T. Yamaguchi, and A. Hara, "Acoustic analysis using finite element method considering effects of damping caused by air viscosity in audio equipment," Applied Mechanics and Materials, vol. 36, pp. 282-286, 2010.

[14] T. Yamamoto, LoudSpeakers System, Radio Technology, Tokyo, Japan, 1977.

[15] K. Hashimoto, M. Sakane, M. Ohnami, and T. Yoshida, "Development of vibrating reed machine for measuring Young's modulus of thin films," Journal of the Society of Materials Science, Japan, vol. 44, no. 507, pp. 1456-1463, 1995.

[16] T. Saeki, LoudSpeakers \& Enclosure, SeiBunDo ShinKoSha, Tokyo, Japan, 1999.

[17] X. Zhao, "Some new problems and measure with structural optimization software development," in Proceedings of the Conference on Computational Engineering and Science (ICCS '07), vol. 12, no. 1, pp. 129-132, Beijing, China, 2007.

[18] X. Zhao, Y. Hu, and I. Hagiwara, "Optimal design for crash characteristics of cylindrical thin-walled structure using origami engineering," The Japan Society of Mechanical Engineers, vol. 76, no. 761, pp. 10-17, 2010. 


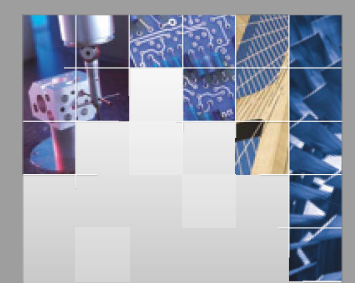

\section{Enfincering}
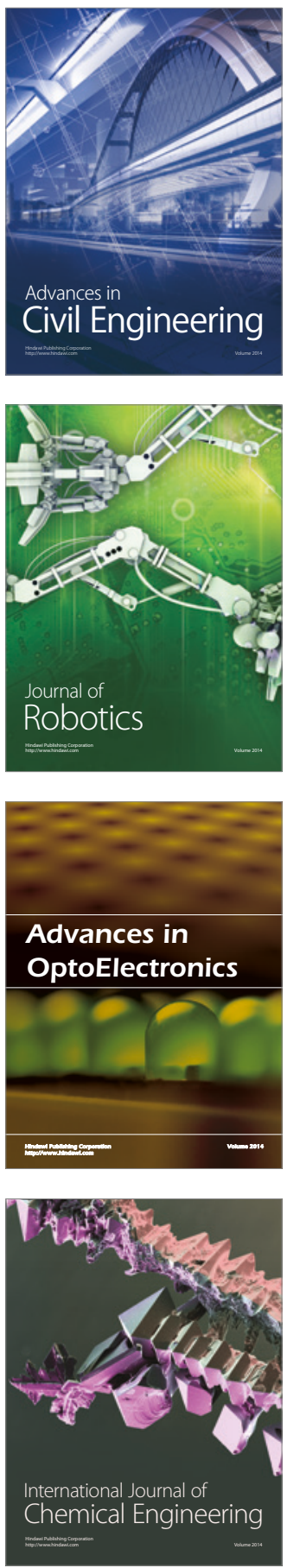

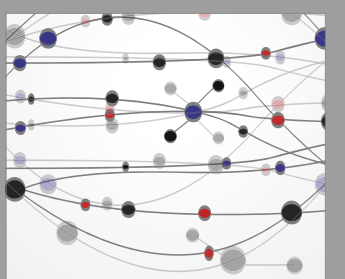

The Scientific World Journal

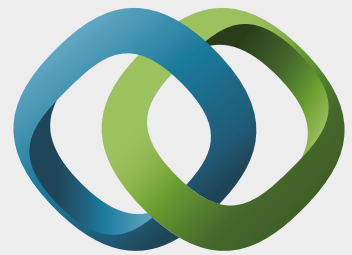

\section{Hindawi}

Submit your manuscripts at

https://www.hindawi.com
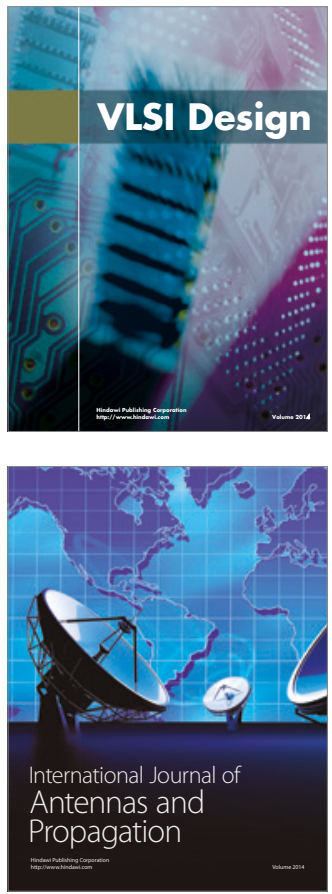

\section{Rotating}

Machinery
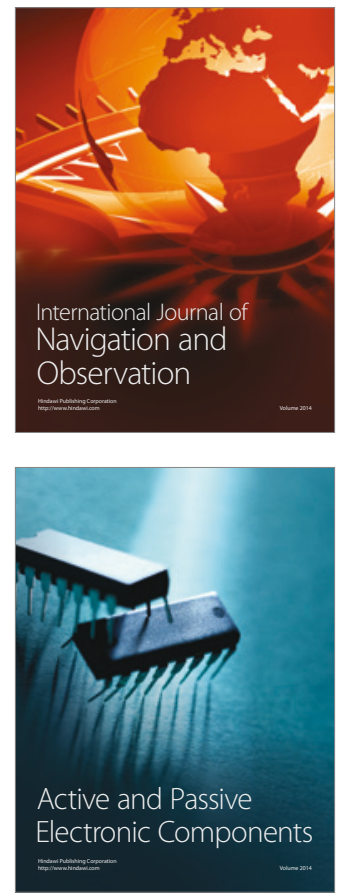
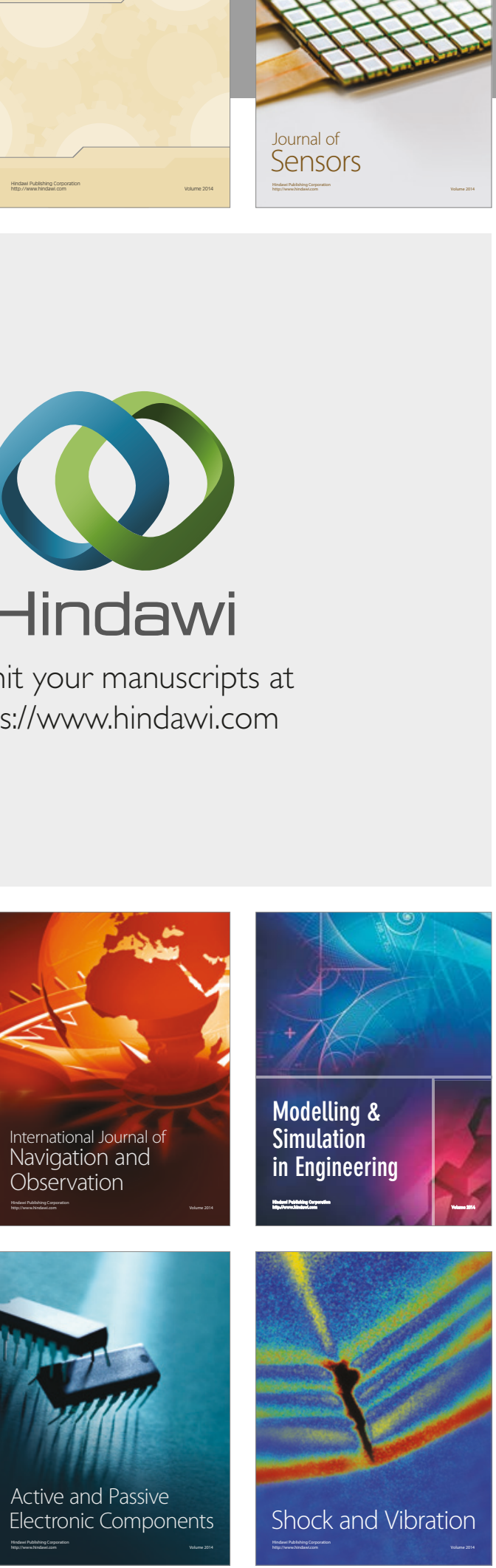
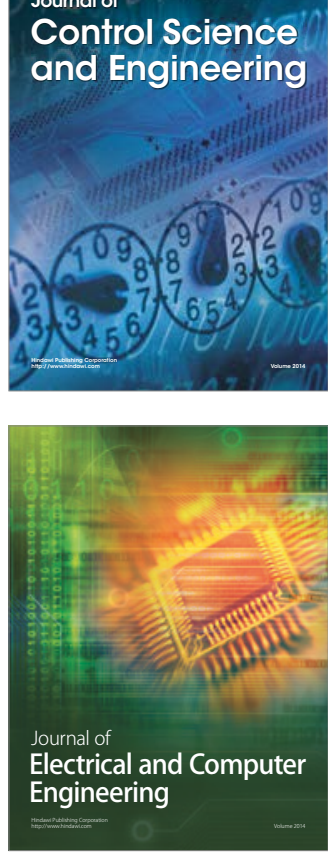

Distributed

Journal of

Control Science

and Engineering
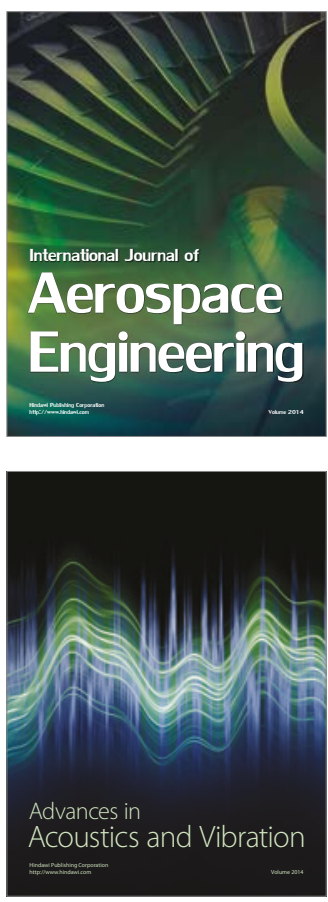

Sensor Networks 